7 (2016)

D0I: $10.18276 /$ rk.2016.7-07

Elżbieta Binczycka

Uniwersytet Jagielloński

\title{
Animist realism. \\ Współczesne mitoznawstwo a komparatystyka literacka
}

W niniejszym artykule, którego tytuł pomyślany został nieco na wyrost, chciałabym zająć się kategorią realizmu animistycznego i wskazać mit jako główny czynnik konstruujący narracje, które moglibyśmy do tej kategorii przyporządkować. Projekt, o którym tu opowiadam, jest z definicji komparatystyczny i otwiera, moim zdaniem, bardzo ciekawe perspektywy dla literaturoznawstwa porównawczego. Sam termin animist realism nie stał się jeszcze dotąd obiektem analizy polskich badaczy, niniejszy artykuł stanowi więc w pierwszej kolejności próbę wprowadzenia tej interesującej kategorii do rodzimego literaturoznawstwa. Próbę tę podejmuję z całą świadomością niepewności gruntu, po którym będziemy tu stąpać - pojęcia takie jak „animizm”, „realizm”, „mit” doczekały się w naukach humanistycznych bardzo wielu definicji. Niewykluczone również, że kategoria realizmu magicznego, bardzo interesująco redefiniowana przez Katarzynę Mroczkowską-Brand w jej ostatniej książce Przeczucia innego porządku. Mapa realizmu magicznego w literaturze światowej XX $i$ XXI wieku może okazać się wystarczająca do badania opisywanych tu zjawisk.

Użyty przez kilku zachodnich badaczy termin animist realism definiowany był dotychczas dość nieostro, dlatego niniejszy artykuł stanowi także próbę doprecyzowania tego zjawiska, różniącego się od szeroko pojętego realizmu magicznego kilkoma istotnymi cechami.

\section{Realizm animistyczny}

Mity i wierzenia religijne są bezsprzecznie bardzo silnie obecne w najnowszej powieści postkolonialnej na wszystkich szerokościach geograficznych. Dotychczas narracje te analizowano raczej $\mathrm{w}$ kategoriach realizmu magicznego, jak robi to Katarzyna Mroczkowska-Brand we wspomnianej już wyżej książce Przeczucia 
innego porządku. Badaczka zajmuje się w niej, obok Gabriela Garcii Marqueza, takimi autorami, jak posiadająca ojibwejskie korzenie amerykańska pisarka Louise Erdrich, afroamerykańska noblistka Toni Morrison czy norweski pisarz i szaman saamskiego pochodzenia Ailo Gaup, znany polskiemu czytelnikowi jako autor powieści Trommenreisen (Podróż na dźwiękach szamańskiego bębna).

Zanim spróbuję odpowiedzieć na pytanie, czym jest tytułowy realizm animistyczny i jak różni się on od wspomnianego przed chwilą realizmu magicznego, przypomnę dla porządku, czym jest sam animizm, cytując w tym celu jedną z najbardziej klasycznych prac religioznawczych dotyczących tego tematu:

Pod nazwą animizmu zamierzam badać głęboko zakorzenioną naukę o duchach, czyli istotach nadprzyrodzonych, która przedstawia zasadnicze pojęcie filozofii spirytystycznej w przeciwieństwie do materialistycznej. Wyraz „animizm” nie jest nowym, chociaż obecnie rzadko bywa używanym. Będąc zastosowanym specjalnie do nauki o duszy, okazuje się on bardzo odpowiednim do określenia poglądów na sposób rozwoju pojęć teologicznych w ludzkości. Nazwa spirytyzm, jakkolwiek używaną była nieraz w znaczeniu ogólnem, ma tę widoczną wadę, że stała się imieniem sekty nowożytnej, która głosi poglądy spirytystyczne, ale nie może służyć za typ tych poglądów na całym świecie. Animizm tedy będzie tu oznaczał ogólną naukę o istotach nadprzyrodzonych

(Tylor, 1896: 350)

- pisze Edward Burnett Tylor w swoim, wydanym w 1871 roku, tekście zatytułowanym Primitive Culture i wydanym po polsku jako Animizm. Kultura pierwotna. Od tamtego czasu podejście do religii animistycznych nieco ewoluowało, zmieniło się też podejście badaczy do samych kultur tradycyjnych. Pomimo iż nikt nie uważa dziś, ażeby animizm był „cechą plemion stojących na bardzo niskim poziomie kultury”, w potocznym rozumieniu wciąż można spotkać się z przekonaniem, iż w wierzeniach animistycznych „bóstwami” są kamienie czy drzewa. Zwraca na to uwagę afrykański literaturoznawca Harry Garuba, w którego artykule czytamy:

Perhaps the single, most important characteristics of animist thought - in contrast to the major monotheistic religions - is its almost total refusal to countenance unlocalized, unembodied, unphisicalized gods and spirits. Animism is often simply seen as a belief in objects such as stones or trees or rivers for the simple reason that animist gods and spirits are located and embodied in objects: the objects are the physical and material manifestations of the gods and spirits. Instead of erecting graven images to symbolize the spiritual being, animist thought spiritualizes the object world, thereby giving the spirit a local habitation.

(Garuba, 2003: 276) 
W mojej refleksji nad animizmem w literaturze odniosłam się do klasycznej pracy Tylora, ponieważ w swojej koncepcji zwraca on uwagę na kluczową rolę dusz i duchów, ${ }^{1}$ ale sam animizm pojmuje nieco szerzej: jako sposób wierzenia społeczności tradycyjnych w ogóle. Podkreślam tę kwestię, ponieważ sama chciałabym pójść w stronę podobnego rozumienia animizmu - nie jako samej „wiary w duchy", ale jako pewnej formy religijności w społecznościach plemiennych, której zasadniczym rdzeniem jest przekonanie o tajemniczości i złożoności otaczającego świata, w którym to, co empirycznie sprawdzalne, stanowi tylko ułamek realnie istniejącej rzeczywistości.

W tym miejscu warto także podkreślić, iż koncepcja animizmu jest w Primitive Culture bardzo mocno powiązana z tylorowskim rozumieniem mitu, dla którego punkt wyjścia stanowi właśnie doświadczenie. Mit u Tylora jest nie metaforą, ale odpowiedzią na pytanie o prawdziwą naturę rzeczy. Jest formą dyskursu, metodą mówienia o świecie, sposobem nadawania mu sensu. Marin D. Stringer w swoim artykule Rethinking Animism: Thoughts From The Infancy of Our Discipline pisze2:

Myths, according to Tylor, begins with experience; that is, with nature and the animation of nature as held by those who believe. The sun and the moon, for example, are generally seen as animate, as the stars, waterspouts, rainbows, disease, death and so on. This is not simply metaphor for Tylor. It is an a priori view of the world, 'philosophy of the nature of things'.

(Stringer, 1999: 548)

Określenie animist realism po raz pierwszy użyte zostało w artykule Harry’ego Garuby zatytułowanym Ben Okri: Animist Realism and the Famished Genre (1993), poświęconym powieści Okri'ego The Famished Road, znanej polskiemu czytelnikowi jako Droga bez dna. Tytułowy animist realism został tu uznany po prostu za dominantę stylu Okri' ego, zaś znaczenie tego terminu doprecyzował Garuba dopiero w kolejnych publikacjach. W swoim kolejnym artykule, Explorations in Animist Materialism (2003), w którym jako przykłady estetyki animistycznej (animist aestetics)

\footnotetext{
Czyni też w tej materii rozróżnienie, które nie jest jednak w tej chwili istotne.

2 Utrzymaną w podobnym duchu refleksję dotyczącą współczesnych form animizmu spotkamy u Briana A. Taylora, w którego artykule Birds, Liminality, and Human Transformation: An Animist Perspective on New Animism czytamy: „Since contemporary animism is emerging from a variety of religious and philosophical traditions it is perhaps best understood as an orientation towards the world. What the many variants share is a sense or belief that the teeming complexity of nature that matrix of interdependent ities of beings that includes humanity as a problematic member species - is pervaded by Spirit and/or mind or consciousness, multiple intelligences, incessant conversation, and relationships of many kinds" (Taylor, 2012: 109).
} 
wymienione zostają, bardzo wyraźne w literaturze afrykańskiej, postaci nienarodzonych i przodków, duchów i bóstw, animizm rozumiany jest jako rodzaj świadomości religijnej przenikającej prozę, poezję czy dramat takich autorów, jak Wole Soyinka, Ben Okri, Amos Tutuola, Toni Morrison czy Chinua Achebe.

W pracach Garuby dość problematyczne wydaje się zastosowanie teorii marksistowskiej, wciąż żywo obecnej w afrykańskim literaturoznawstwie, oraz bardzo szerokie i stosunkowo dowolne pojmowanie omawianego zjawiska. Prowadzi ono autora do przekonania o nadrzędności kategorii realizmu animistycznego wobec kategorii realizmu magicznego. Czytamy: „Animist realism, I believe, is a much more encompassing concept, of which magical realism may be said to be a subgenre, with its own connecting characteristics and its formal difference" (Garuba, 2003: 274). Mimo to sugestywny termin „realizm animistyczny” spotkał się z pewnym zainteresowaniem międzynarodowym. Kanadyjski badacz Ato Quayson w swojej książce Strategic Transformations in Nigerian Writing zwraca na niego uwagę analizując powieści pisarzy nigeryjskich, odcinając się jednak od tezy Garuby o „nadrzędności” realizmu animistycznego nad realizmem magicznym (Quayson, 1997). Artykuł Garuby komentuje również brytyjski religioznawca Graham Harvey w pracy Animist Realism in Indigenous Novels and Other Literature, która ukazała się w wydanym w 2015 roku pod jego redakcją tomie interdyscyplinarnych studiów zatytułowanym The Handbook of Contemporary Animism. Harvey doprecyzowuje tezy Garuby, wskazując na obecność elementów realizmu animistycznego w twórczości autorów innych niż afrykańscy, zaś powieści realizmu animistycznego uznając za typowe dla prozy indygenicznej:

Animist realist novels have a relationship both to the telling of myths and folktales of intimate indigenous pasts and to the necessities of person-, community- and hope-building in the present. Many of their authors are at least bi-cultural and motivated by the potential of storytelling to inspire better futures. The best of them spend little if any time mourning past traditionalisms but, rather, embrace the accumulative, adopting and accommodating potential of animism and narrative. Alongside re-enchantment these works propose a restorying of the world that contrasts with the linearity and supposed fixity of Euro-master-narrative.

(Harvey, 2014: 467)

Dopiero tak pomyślana kategoria realizmu animistycznego wydaje się istotnie interesująca dla komparatystyki literackiej. W niniejszym artykule chciałabym zaproponować pokrewne ujęcie tego tematu, jako zasadniczy składnik powieści realizmu animistycznego wskazując mit - i to właśnie mitowi poświęcić drugą część niniejszego artykułu. 


\section{Mit}

Aby móc przyjrzeć się szerzej problemowi szczególnego znaczenia narracji mitycznych we współczesnej literaturze światowej z punktu widzenia literaturoznawstwa porównawczego, należy odnieść się najpierw do pewnych niejednoznaczności metodologicznych wynikających z różnego postrzegania mitu przez poszczególne dyskursy naukowe.

Jak zauważa religioznawca Maciej Czeremski, pojęcie mitu funkcjonuje w sposób niejednoznaczny zarówno w teoretycznych analizach, jak i użyciu codziennym, stąd kategoria ta wymaga zazwyczaj każdorazowego zdefiniowania, zgodnie z profilem jego wykorzystania w aktualnie zaplanowanym opisie (Czeremski, 2009: 13). Sam Czeremski w swoim opracowaniu Struktura mitów daje szeroki wykład dotyczący zakresu znaczeniowego pojęcia „mit” oraz waloryzacji mitu od czasów starożytnych aż po romantyzm. Podobne omówienie znaleźć można w książce Krzysztofa Piątkowskiego Mit - Historia - Pamięć, artykule Sławomira Sztajera Mit-język rzeczywistość oraz w licznych artykułach i publikacjach z dziedziny mitoznawstwa i literaturoznawstwa w języku angielskim (Roksqandic, 2012; Burnett, Bahun, Main, 2013). W przypadku kategorii, jaką jest mit, literaturę podmiotu można byłoby mnożyć w zasadzie bez końca, ponieważ, jak zauważa Sztajer:

Problematyka mitu jest niezwykle złożona. Duża liczba różnych koncepcji mitu nie jest jedynym problemem, z którym badacze mitów muszą się współcześnie borykać. Mit - tak czy inaczej rozumiany - występuje w wielu kontekstach kulturowych. Antropolodzy, filozofowie kultury oraz religioznawcy zwracają uwagę na odmienne formy i sposoby funkcjonowania opowieści mitycznych w społeczeństwach tradycyjnych i współczesnych. (...) Mit staje się ważnym przedmiotem zainteresowań nie tylko badaczy przeszłości, ale także myślicieli zajmujących się społeczeństwami współczesnymi. Dostrzega się jego obecność nie tylko w religii, ale we wszystkich dziedzinach kulturowej działalności współczesnego człowieka.

(Sztajer, 2006: 60-61)

Sztajer określa swój przedmiot badań mianem „mitu religijnego”, odróżniając go tym samym od wszystkiego, co będzie mitem nie-religijnym. Podobnego, choć dużo szerzej zakrojonego podziału, dokonuje polski filozof i socjolog Józef Niżnik, klasyfikujący teorie mitoznawcze ze względu na rozumienie samego obiektu ich badań (Niżnik, 1978).

Niżnik wyodrębnia wprawdzie stanowisko filologiczne, którego najbardziej lakonicznym wyrazem stała się wypowiedź Rolanda Barthesa o tym, że „mit jest słowem” (Barthes 2000, 239), ujęciu proponowanemu przeze mnie jest jednak 
o wiele bliżej do stanowiska „filozoficzno-antropologicznego”, postrzegającego mit jako ekspresję specyficznej struktury świadomości. Jak pisze Ewa Nowicka w swoim artykule Sporne problemy w badaniach nad mitem,

[m]yślenie mityczne znamionuje (...) znaczny stopień etnocentryzmu w tym sensie, iż brak jest w nim kategorii uniwersalnych, które stosowałyby się do wszystkich ludzi. Mit z założenia jest zespołem treści jednej kultury. Nie interesuje się porządkiem społecznym innych zbiorowości. Jako uzasadnienie społecznego porządku, instytucji i wzorów postępowania mity z natury rzeczy ograniczają swoje zainteresowania do danej zbiorowości.

(Nowicka, 1984: 87)

Ujęcie Nowickiej, choć typowe dla studiów antropologiczno-kulturowych, nie jest zbyt powszechne we współczesnej komparatystyce literackiej, na co zwraca uwagę Adam F. Kola w swoim artykule Po co "mit” literaturoznawstwu?, gdzie mówi o nieprzystawalności kategorii, którymi posługuje się nauka o literaturze, mających swoje korzenie w badaniach nad kulturami czasowo bądź przestrzennie odległymi od naszej.

Bywa, że mity stanowią punkt wyjścia funkcjonowania określonych postaci w literaturze, niemniej jednak genealogia nie czyni z nich mitów sensu stricto. Nie są one bowiem niczym innym jak literacką fikcją, fantazją funkcjonującą w samym dziele literackim na zasadzie intertekstualnego odwołania, zaś w życiu literackim jak figury wyobrażeniowego świata. (...) Ani Don Juan, ani Faust czy Don Quijote nie są w tej optyce mitami. Nie odgrywają bowiem żadnej z podstawowych dla mitów ról

(Kola, 2012: 82)

- pisze Kola, podkreślając równocześnie kolektywny charakter mitu, jego wspólnotową, jednoczącą i często także założycielską dla grupy rolę, bez której kategoria ta nie może być używana. Zdaniem Koli mity literackie „nie mają przede wszystkim owej mocy społecznej powszechności, zrozumiałości, dostępności, eksplikacyjności. Są jedynie realizacją pewnej autorskiej wizji korzystającej z motywów (nie mitów!) wcześniej w literaturze funkcjonujących (Kola, 2012: 83). Z tej przyczyny należałoby ograniczyć używanie tej kategorii jedynie do przypadków uzasadnionych.

(...) by nie rozwadniać w kontekście euro-amerykańskim mitu, by nie osłabiać mocy wyjaśniającej owej kategorii, nie możemy stosować jej w odniesieniu do figur literackich, zjawisk w pełni dających się wytłumaczyć pojęciami, takimi jak: motyw, intertekstualność, konwencje literackie, czy za pomocą narzędzi wypracowanych m.in. w ramach szeroko pojmowanej socjologii literatury i badań nad recepcją 
i przepływami motywów literackich pomiędzy różnymi kulturami w następujących po sobie okresach itd.

(Kola, 2012: 89).

Nadużywanie terminu „mit” w literaturoznawstwie, niezwykła pojemność i uniwersalność tej kategorii oraz identyfikowanie badań nad mitem w literaturze $\mathrm{z}$ badaniami nad topiką biblijną lub motywami antycznymi nastręczają tu pewnych problemów, podobnie jak potoczne rozumienie mitu jako fałszu, stosunkowo szeroko stosowane w pracach badaczy związanych z nurtem studiów postkolonialnych.

W teorii postkolonialnej do kategorii mitu sięga się przede wszystkim w dyskursie dotyczącym imperializmu i globalnego podporządkowania. I tak Edward Said zajmuje się mitem Orientu (Orientalism), Frantz Fanon mitem białego człowieka (Black Skin, White Masks), Édouard Glissant mitem asymilacji (Poétique de la Relation), Dorothy Hammond i Alta Jablow mitem Afryki (The Myth of Africa), Martin Lewis i Kären Widgen mitem kontynentów (Myth of Continents) itd. Tak rozumiany mit jest nie tylko rodzajem ideologii i formą władzy, ale także rodzajem mistyfikacji i manipulacji. Również Gayatri Spivak w swoim projekcie komparatystyki inkluzywnej, a więc „włączającej”, postuluje walkę z tak rozumianymi „mitami” twierdząc, iż odpowiedzialna komparatystyka „musi podejść do kulturowo zróżnicowanego systemu etycznego diachronicznie, poprzez historię imperiów wielokulturowych, bez przesądzania z góry wniosków (Spivak, 2010: 174).

Wśród tych słusznych, choć miejscami utopijnych założeń, pozornie tylko nie ma miejsca na przewartościowanie i dowartościowanie mitu jako podstawowej ekspresji kultury Innego.

Jak przyznaje Spivak w swoim tekście Komparatystyka jako instytucja, „oddanie głosu Innemu” w badaniach komparatystycznych wcale nie jest łatwym zadaniem i często może sprowadzać się do zaproszenia profesora z odleglejszego ośrodka akademickiego, aby wygłosił gościnny wykład w języku angielskim, zaś znajomość większej ilości „języków Południa” jest często zwyczajnie niemożliwa. W takiej sytuacji wydawać by się mogłoby się, iż Inny nie zostanie w końcu dopuszczony do głosu. Perspektywą niosącą nadzieję na zmianę tego stanu może być właśnie przewartościowanie spojrzenia na mit w komparatystyce literackiej. W przywoływanym wcześniej artykule Kola pisze:

W procesie upowszechniania komparatystycznego namysłu winniśmy porzucić roszczenia pozornie uniwersalnych kategorii, które de facto są silnie zakorzenione w zachodniej tradycji intelektualnej. Trzeba je zdekonstruować, wskazując na ich 
kulturowe zaplecze. Uczyniono to z (...) „literaturą światową”. Teraz przyszedł czas na inne pojęcia.

Wspomnianą redefinicję pojęcia „literatury światowej” zaproponował już Damrosch, zaś kolejnym terminem czekającym na zreinterpretowanie jest właśnie „mit”, choć „pozostawienie go rzeczywistości społecznej”, które postuluje w swoim tekście Kola, może okazać się z jednej strony niewykonalne, z drugiej zaś niepotrzebne. Zamiast tego należałoby spróbować przywrócić badaniom komparatystycznym mit w jego antropologiczno-religioznawczym rozumieniu. Możliwość tę daje nam sama literatura, nawet ta tworzona w językach kolonizacji, jeśli tylko potraktujemy jej mity z należytą powagą, zaś badanie obecności mitu we współczesnej literaturze postkolonialnej jest być może jedyną szansą na prawdziwą komparatystykę inkluzywną w formie, w jakiej rozpatruje ją Spivak. Aby wykroczyć poza literaturę, nie tylko w stronę innych form kulturowej ekspresji, ale także w stronę historii, socjologii, religioznawstwa, potrzebujemy nowych kategorii będących równocześnie płaszczyznami porównania. Jedną z takich płaszczyzn może stać się właśnie tytułowy animist realism - realizm animistyczny.

\section{Główne cechy realizmu animistycznego}

Narracje realizmu animistycznego, nawet jeśli pisane są w językach byłych imperiów kolonialnych, umożliwiają równocześnie dostęp do unikalnych treści kultur, które w tym modelu moglibyśmy określić - za pomocą języka mitu - mianem „peryferyjnych”. O przynależności danej narracji do kręgu prozy animist realism świadczyłaby przede wszystkim obecność wierzeń animistycznych, a zwłaszcza obecność mitów społeczności tradycyjnych i wynikające z tego konsekwencje w prowadzeniu narracji powieściowej oraz alternatywna wobec zachodniej koncepcja „realności”, a więc co za tym idzie - również i realizmu. Wskazanie mitu jako naczelnego składnika powieści realizmu animistycznego pozwala na wyodrębnienie i analizę składników typowych dla tych narracji, którymi są:

- obecność postaci tricksterskich lub innych herosów kulturowych, duchów, przodków, elementów rytualnych i szamańskich,

- obecność oratury w literaturze: motyw ustnego przekazu, opowieść w opowieści, (mające swoje odbicie również w warstwie konstrukcyjnej tekstów), jak to ma miejsce np. w powieściach wspomnianej już tutaj Louise Erdrich, 
- sakralno-magiczne znaczenie imion, nazywania i języka w ogóle, co powiązane jest też z obecnością w tej prozie odwołań do rytów inicjacyjnych, których składnikiem jest między innymi nadanie nowego imienia,

- $\quad$ rola kobiety jako osoby przekazującej treści kulturowe, jak ma to miejsce w społecznościach tradycyjnych, w których do czasu inicjacji zarówno chłopcy, jak i dziewczęta są wychowywani i uczeni podstaw kultury przez kobiety właśnie3,

- nawiązanie do konkretnych narracji mitycznych i folklorystycznych, np. mitu Flying Africans, opowieści o Kojocie, Kruku czy Pająku,

- zderzenie kultur/światów i - co za tym idzie - obecność synkretyzmu religijnego: mit nie-chrześcijański często będzie tu świadomie zestawiany z mitem chrześcijańskim, jak robi to np. Toni Morrison we wspomnianej powieści Song of Solomon (gra znaczeń podjęta jest już wyraźnie w samym tytule powieści),

- specyficzna konstrukcja czasu i przestrzeni (objawiająca się np. odwołaniami do czasu sakralnego, cyklu kosmicznego, plemiennych koncepcji samego kosmosu etc.),

- problem poszukiwania tożsamości i powrotu do korzeni, zagubienie międzykulturowe, fenomen pamięci i postpamięci oraz powiązany z nim problem intencji autorskiej - autorzy powieści z kręgu realizmu animistycznego to przede wszystkim autorzy literackiego „globalnego Południa”.

W tak zarysowanym projekcie interpretacja dzieł literackich przeprowadzona powinna być ze szczególnym zwróceniem uwagi na problem uniwersalności/partykularności treści kulturowych, której świadomi są także sami autorzy ${ }^{4}$. Pokusę sprowadzania treści jednej kultury tradycyjnej do innej zaszczepił w nas już Eliade, używając terminu „mana” na oznaczenie wielu różnorodnych i niekoniecznie przystających desygnatów obecnych w wierzeniach rozmaitych społeczności, zaś sam problem translacji kulturowej towarzyszy człowiekowi od pierwszej chwili,

3 W tym miejscu miłośnikom twórczości Toni Morrison przychodzi niemal od razu na myśl motto jej powieści Song of Solomon: „The fathers may soar. And the children may know their names” nie do końca szczęśliwie oddane w polskim przekładzie jako „Ojcowie mogą sobie bujać, a dzieci mogą znać ich imiona”. Chodzi tutaj o odwołanie do mitu Flying Africans, będącego osią konstrukcyjną dla całej powieści. W micie tym niewolnicy zmieniają się w ptaki i odlatują do Afryki. Jak pisze Gay Wilentz w swoim artykule Civilizations underneath: “(...) there is a group missing from the dedication whose presence is overpowering in the novel itself - the mothers (grandmother, aunt, older sibling, female ancestor). When the father soars off, there must be someone left to teach the children their names" (Wilentz, 2014: 64).

4 Dobrym przykładem może być tu problem interpretowania mitu Flying Africans obecnego w Song of Solomon jako kolejnego wariantu mitu ikaryjskiego. 
w której spróbował on opisać kulturę Innego we własnym języku5.$Z$ tego powodu re-definicja podstawowych kategorii, jakimi posługujemy się, poszukując znaczenia w tekstach kulturowo nam obcych, wydaje się nieunikniona. Jak pisze Kola:

W procesie upowszechniania komparatystycznego namysłu winniśmy porzucić roszczenia pozornie uniwersalnych kategorii, które de facto są silnie zakorzenione w zachodniej tradycji intelektualnej. Trzeba je zdekonstruować, wskazując na ich kulturowe zaplecze. Uczyniono to z (...) „literaturą światową”. Teraz przyszedł czas na inne pojęcia.

(Kola, 2012, 84)

Najbardziej problematycznym z tych pojęć jest najprawdopodobniej „mit”. Andrzej Szyjewski twierdzi, że w naszej współczesnej, zachodniej kulturze szczególnie trudno jest go odbierać, rozumieć, mieć na niego wrażliwość, najprawdopodobniej dlatego, iż nasze wykształcenie jako modelową promuje mitologię grecką, stanowiącą olbrzymi korpus rozbudowanych, wielowątkowych historii już od samego początku literacko przetworzonych. Nie znamy mitów, które opowiadali Grecy - wiemy, o czym pisali greccy historycy i poeci, zaś w szkole, a nawet na studiach, poznajemy jeszcze bardziej przetworzoną i zbeletryzowaną wersję mitologii greckiej, którą daje nam Parandowski. Tymczasem mit jest wyjściowo oralny, związany z opowiadaniem. W społeczności, w której mity są opowiadane, są one znane i słuchanie ich pozbawione jest „elementu zaskoczenia”.

5 W tym miejscu czoła powinniśmy stawić również problemowi „uniwersalności” kodów kulturowych, który bardzo dobrze zobrazowany został w tekście amerykańskiej antropolożki Laury Bohannan, która podczas prowadzonych przez siebie w 1966 roku w południowej Nigerii badań, postanowiła zapoznać lokalnych Tiw z uniwersalną wartością szekspirowskiego Hamleta. Cała przygoda zaczęła się od sporu z przyjacielem dotyczącego niepełnego odczytania Szekspira na gruncie kultury amerykańskiej. Jak relacjonuje sama Bohannan: „I protested that human race is pretty the same the whole world over; at least the general plot and motivation of the greater tragedies would always be clear - everywhere - although some details of custom might have to be explained and difficulties of translation might produce other slight changes" (Bohannan, 1966: 28). Jakież było zdziwienie badaczki, gdy okazało się, że nie tylko Tiw odczytują opowiedziany im dramat zupełnie inaczej, ale także przekonani są o tym, iż to właśnie ich odczytanie jest słuszne i właściwe. W konkluzji artykułu Bohannan znajdziemy słowa członka plemiennej starszyzny: „Sometime (...) you must tell us some more stories of your country. We, who are elders, will instruct you of their true meaning, so when you return to your own land your elders will see that you have not been sitting in the bush, but among those who know things and who have thought you wisdom" (Bohannan, 1966: 33).

6 Pod wpływem wychowania na mitologii greckiej niemiecki etnolog Carl Strehlow, który jako pierwszy dokonał próby zapisu mitów aborygenów australijskich, pominął w nich bardzo do- 
Komparatystyczna analiza tekstów z kręgu realizmu animistycznego powinna zostać przeprowadzona z naciskiem na problem podwójności kodów kulturowych. Na płaszczyźnie realistyczne/nierealistyczne podwójności tej świadomi są już autorzy, którzy często sami dają czytelnikowi możliwość dwojakiej interpretacji swoich powieści. Czytać można je metaforycznie bądź dosłownie, a wiara w nie-realistyczne elementy narracji zależy od samego czytelnika, który pewne wydarzenia i opisy może zaakceptować z całą ich „magicznością” bądź zracjonalizować - przenosząc je do sfery snu, a nawet zrzucić na karb wybujałej wyobraźni lub niestabilności psychicznej poszczególnych bohaterów. Dotarcie do sensu narracji mitycznej zakłada wprawdzie wiarę $\mathrm{w}$ prawdziwość opowiadanej historii, ale wiara ta nie jest z góry narzucona czytelnikowi powieści.

Przedmiotem badań literaturoznawczych w projekcie dotyczącym realizmu animistycznego byłyby dla mnie przede wszystkim utwory, które powstały w ciągu ostatnich kilkudziesięciu lat i wyszły spod pióra autorów identyfikujących się z kulturami i społecznościami tradycyjnymi, a którzy podejmowali w swojej prozie problematykę tożsamości kulturowej, kolonializmu i kulturowej dominacji. Proponowane tutaj ujęcie realizmu animistycznego kładzie szczególny nacisk na konstytuowanie się narracji powieściowych wokół treści zaczerpniętych z mitów i wierzeń społeczności tradycyjnych, widoczne w prozie takich autorów współczesnych, jak Louise Erdrich, Toni Morrison, Gloria Naylor, Ben Okri, Ailo Gaup, Leslie Marmon Silko, James Welch, Paule Marshall czy Peter Carey.

Wskazanie różnic i ukonstytuowanie punktów wspólnych pomiędzy kategorią animist realism, fantastyką czy narracjami realizmu magicznego zasługuje na osobne omówienie z uwagi na nieostrość i różnice $\mathrm{w}$ definiowaniu powyższych pojęć. Ciekawie rysuje się również relacja pomiędzy realizmem animistycznym a literackim postmodernizmem, która bardzo interesującą realizację znajduje np. w tekstach Shermana Alexie, Ishmaela Reeda czy Thomasa Kinga. Wart omówienia jest tu także problem intencji autorskiej, szczególnie przecież istotny, gdy mowa o prozie postkolonialnej. Być może to wysiłek autora tekstu, by oddać głos temu, kto pozbawiony był prawa głosu, ocalić, niejednokrotnie ginącą już, tradycję, kulturę, opowieść, decydują o tym, że powieści Louise Erdrich wydają się intuicyjnie bliższe kategorii animist realism niż twórczość np. Salmana Rushdiego, przynależąca bardziej do kręgu realizmu magicznego. Istotne jest tutaj bowiem nie tylko samo użycie mitu, ale również stosunek do niego.

kładne opisy strojów i rytuałów, które dla Aranda, o których tutaj mowa, są ich najważniejszym elementem. 
W rozumieniu mitoznawczym i religioznawczym, które, mam nadzieję, udało mi się tu pokrótce zaprezentować, mit nie jest fałszem. W ujęciach, ku którym się skłaniam, nie stanowi również kategorii uniwersalnej, wspólnej wielu kulturom. Dotyczy społeczności, z której się wywodzi, ma swoje specyficzne znaczenie. Wyjściowo jest zjawiskiem oralnym. W jego naturze leży zmienność, stąd tematy i motywy mityczne wędrują w obrębie kultury. Dopiero na takie pojmowanie mitu chciałabym nałożyć kolejną, szerszą perspektywę: filologiczną i komparatystyczną, która każe nam szukać uniwersalnego w tym, co partykularne. Kategoria animist realism daje nam taką możliwość, ponieważ pozwala na zauważenie podobieństw w tekstach literackich wywodzących się z różnych tradycji i kultur, przy jednoczesnym uznaniu ich unikatowości. Jak pisze Louise Erdrich: „Our songs travel the earth. We sing to one another. Not a single note is ever lost and no song is original. They all come from the same place and go back to a time when only the stones howled" (Erdrich, 2002: 388).

\section{Bibliografia}

Barthes, Roland. Mitologie. Przeł. Adam Dziadek. Warszawa: Wydawnictwo KR, 2000.

Bohannan, Laura. „Shakespeare in the Bush. An American anthropologist set out to study the Tiv of West Africa and was taught the true meaning of Hamlet". Natural History 66 (1975): 28-33.

Czeremski, Maciej. Struktura mitów: W stronę metonimii. Kraków: Nomos, 2009.

Garuba, Harry. „Explorations in Animist Materialism: Notes on Reading/Writing African Literature, Culture, and Society". Public Culture 15.2 (2003): 261-285.

Harvey, Graham. „Animist Realism in Indigenous Novels and Other Literature”. The Handbook of Contemporary Animism. Ed. Harvey Graham. London: Routledge, 2014: 454-467.

Kola, Adam F. Po co „mit” literaturoznawstwu? „Komparatystyka między Mickiewiczem a dniem dzisiejszym". Red. Lidia Wiśniewska. Bydgoszcz: Wydawnictwo Uniwersytetu Kazimierza Wielkiego w Bydgoszczy, 2012: 81-90.

Myth, Literature, and the Unconscious. Eds. Leon Burnett, Sanja Bahun, Roderick Main. London: Karnac Books, 2013.

Niżnik, Józef. „Mit jako kategoria metodologiczna”. Kultura i Spoteczeństwo 22 (1978): $163-174$.

Nowicka, Ewa. „Sporne problemy w badaniach nad mitem”. Kultura i Spoteczeństwo 28.3 (1984): 87-101. 
Roksqandic, Ivan. The Ouroboros Seizes Its Tale. Strategies of Mythopeia in Narrative Fiction From The Mid-fifties to the Mid-seventies: Six Examples. Vancouver: Lambert Academic Publishing, 2002.

Spivak, Gayatri Chakravorty. „Przekraczanie granic”. Niewspótmierność. Perspektywy nowoczesnej komparatystyki. Antologia. Red. Tomasz Bilczewski. Kraków: Wydawnictwo Uniwersytetu Jagiellońskiego, 2010: 161-184.

Stringer, Martin D. „Rethinking Animism: Thoughts From The Infancy of Our Discipline". Journal of the Royal Anthropological Institute 5.4 (1999): 541-556.

Sztajer, Sławomir. „Mit - język - rzeczywistość. Mityczno-rytualna kreacja i odtwarzanie uniwersum religijnego". Przegląd Religioznawczy 1.219 (2006): 60-61.

Taylor, Brian Anthony. „Birds, Liminality, and Human Transformation: An Animist Perspective on New Animism”. The Pomegranate 1.14 (2012): 108-127.

Tylor, Edward Burnett. Animizm. Cywilizacja pierwotna. Przeł. Jan Karłowicz. Warszawa: Głos 1896.

Quayson, Ato. Strategic Transformations in Nigerian Writing: Orality and History in the Work of Rev. Samuel Johnson, Amos Tutuola, Wole Soyinka and Ben Okri, Bloomington: Indiana University Press, 1997.

Wilentz, Guy. "Civilizations Undereath: African Heritage as Cultural Discourse in Toni Morrison's Song of Solomon.” African American Review 26.1 (2014): 61-76.

\section{Animist Realism.}

\section{Between Contemporary Myth Studies and Comparative Literature}

\section{Summary}

Animist realism, introduced by Harry Garuba in his article Ben Okri: Animist Realism and the Famished Genre is a relatively new term. Garuba links it to African literature, while others (Ato Quayson, Graham Harvey) use it in association with a broader spectrum of fiction. The main objective of this article is to redefine the category of animist realism as a subgenre of magical realism with its own connecting characteristics and its formal difference. Author of the article argues that animist realism is applicable especially to postcolonial and indigenous literature permeated with myths and other elements derived from traditional belief systems.

Keywords: comparative literature, animist realism, magic realism, myth, postcolonial literature, myth studies

Słowa kluczowe: komparatystyka literacka, realizm animistyczny, realizm magiczny, mit, literatura postkolonialna, mitoznawstwo 